\title{
Human Adenine Phosphoribosyltransferase: Characterization from Subjects with a Deficiency of Enzyme Activity
}

\author{
Timothy E. O' Toole, ${ }^{1}$ James M. Wilson, ${ }^{1}$ M. Henry Gault, ${ }^{2}$ and William N. \\ Kelley ${ }^{\text {I }}$
}

Received 2 Mar. 1983-Final 18 May 1983

Adenine phosphoribosyltransferase (APRT) was characterized with respect to specific activity and immunoreactive protein (CRM) levels in hemolysate from 18 members of an APRT-deficient kindred. In addition, lymphoblastoid cell lines were established from six of these subjects and APRT from these cells was characterized in a similar fashion. Levels of specific activity and CRM in patients homozygous for the deficiency were less than $1 \%$ of normal. Heterozygous subjects had higher levels of activity and CRM in lymphoblasts than in erythrocytes and, in all cases, the APRT present was normal in terms of isoelectric point, subunit molecular weight, and heat stability. The higher levels of activity and CRM found in lymphoblasts may be due either to expression of a mutant gene product stabilized in a normal:mutant dimer or to autologous regulation.

KEY WORDS: adenine phosphoribosyltransferase (APRT) deficiency; protein blotting; lymphoblastoid cells; inborn errors of metabolism.

\section{INTRODUCTION}

Adenine phosphoribosyltransferase (APRT; EC 2.4.2.7) is a purine salvage enzyme catalyzing the formation of AMP from adenine and PP-ribose-P. A deficiency of the enzyme in humans is inherited in an autosomal recessive

\footnotetext{
1 Departments of Internal Medicine and Biological Chemistry, Human Purine Research Center, University of Michigan Medical School, Ann Arbor, Michigan 48109.

${ }^{2}$ Health Sciences Center, Department of Medicine, Memorial University of New Foundland, St. Johns, New Foundland.
} 
manner and is manifested in some homozygotes by the formation of kidney stones composed of 2,8-dioxyadenine (Kelley et al., 1968; Debray et al., 1976; VanAcker et al., 1977). Patients heterozygous for APRT deficiency have no characteristic biochemical or clinical abnormalities (Kelley et al., 1968; Fox et al., 1973).

Although the lack of enzyme activity which leads to the formation of 2,8-dioxyadenine stones has been well documented (Debray et al., 1976; VanAcker et al., 1977; Barratt et al., 1979), little is known about the genetic mechanisms which are responsible for the enzyme deficiency state. Inborn errors of metabolism frequently result from structural gene mutations which render the mutant protein inactive or less active catalytically. Alternatively, such enzymatic defects may be due to a mutation which affects the steady state level of an enzyme with normal catalytic function. Such mutations alter the rates of synthesis or degradation of the protein.

In a previous study we have characterized APRT in hemolysate from a number of families with a deficiency of the enzyme (Wilson et al., 1981a). Our results consistently showed less than $1 \%$ of normal specific activity and immunoreactive protein (CRM) in homozygotes, whereas heterozygotes exhibited approximately $25 \%$ of the normal specific activity and CRM in hemolysate rather than the $50 \%$ of normal levels which would have been expected. This unusual finding in heterozygotes has been explained by the proposal that an APRT dimer containing the product of a mutant allele is unusually labile (Kelley et al., 1968; Wilson et al., 1981a). In effect, it is suggested that there is equal expression of both alleles, with random association of their products, and that only dimers with two normal subunits, or $25 \%$ of the population of APRT molecules, are stable and thus detectable. Because erythrocytes are enucleated and do not synthesize new protein, they may not be the ideal tissue to study this phenomenon. Cultured lymphoblasts, which do synthesize new protein, may be a better tissue for exploring the specific mechanisms responsible for APRT deficiency. In our present investigation we have characterized APRT in hemolysate from a new kindred and have compared our results with those obtained in lymphoblast cell lines derived from members of this kindred. This kindred also represents the first North American APRT-deficient family reported (Gault et al., 1981).

\section{MATERIALS AND METHODS}

\section{Cell Preparation and Extracts}

Fresh blood $(20 \mathrm{ml})$ was obtained from the 18 patients by drawing the samples into heparinized tubes. Half of the blood was centrifuged for $30 \mathrm{~min}$ at $600 \mathrm{~g}$. The plasma and buffy coat were removed by aspiration, while the red cells 
were washed twice with an equal volume of $0.9 \% \mathrm{NaCl}$, lysed by freezethawing, and stored at $-20^{\circ} \mathrm{C}$ until ready for use. In addition, lymphoblast cell lines were established from six of the subjects, including five heterozygotes and one homozygote essentially as described previously (Wilson et al., 1982). Lymphoblast extracts were prepared by harvesting $20-40 \times 10^{6}$ cells growing in log phase, freeze-thawing the cells six times in a small volume $(0.8$ to $1.0 \mathrm{ml}$ ) of $10 \mathrm{mM}$ Tris- $\mathrm{HCl}, p \mathrm{H} \mathrm{7.4}$, containing $154 \mathrm{mM} \mathrm{NaCl}$, and centrifuging for $30 \mathrm{~min}$ in a Beckman airfuge. The final protein concentration of these extracts ranged from 1.0 to $3.0 \mathrm{mg} / \mathrm{ml}$.

\section{APRT Assays}

APRT activity and immunoreactive (CRM) assays were conducted on dilutions of hemolysate or lymphoblast extract. Enzyme activity was assayed by a previously described radiochemical method (Holden et al., 1979). The specific activity is expressed as milliunits of enzyme activity per milligram of protein. One unit of enzyme activity is defined as the amount of enzyme necessary to catalyze the formation of $1 \mu \mathrm{mol}$ of AMP $/ \mathrm{min}$. APRT immunoreactive protein was measured using a previously described radioimmunoassay (Wilson et al., 1981a). Levels of immunoreactive protein were expressed as nanograms of CRM per milligram of protein.

Hypoxanthine-guanine phosphoribosyltransferase activity was assayed as described previously (Holden and Kelley, 1978) and expressed as milliunits of enzyme activity per milligram of protein. One unit of enzyme activity is defined as the amount of enzyme necessary to catalyze the formation of 1 $\mu \mathrm{mol}$ of IMP $/ \mathrm{min}$.

Protein was assayed according to the method of Lowry (Lowry et al., 1951) using bovine serum albumin as the standard.

\section{Isoelectric Focusing and Protein Blotting}

Isoelectric focusing of samples was done as previously described (Wilson et al., 1981a). To aid our focusing and detection techniques, APRT was partially purified from hemolysate before these experiments (Wilson et al., 1981a). Lymphoblast extracts were used without further purification. The protein blotting and immunochemical detection of APRT were done as previously described (Wilson et al., 1981a).

\section{SDS Gel Electrophoresis and Protein Blotting}

Partially purified hemolysate or lymphoblast extract was subjected to SDS gel electrophoresis essentially as described previously (Wilson et al., 1982). 
Proteins were transferred from polyacrylamide gels to nitrocellulose paper by electrophoresis in a BioRad Transblot for $3 \mathrm{hr}$ at $70 \mathrm{~V}$ using buffer A [ $20 \mathrm{mM}$ Tris-base, $p \mathrm{H} 8.0$, including $150 \mathrm{~mm}$ glycine and $20 \%$ methanol $(\mathrm{v} / \mathrm{v})]$. APRT was immunochemically detected as was done for isoelectric focusing blots.

\section{Heat Stability}

Lymphoblast extract $(200-500 \mu \mathrm{l})$ was dialyzed for $24 \mathrm{hr}$ at $2^{\circ} \mathrm{C}$ against buffer $\mathrm{B}(10 \mathrm{mM}$ Tris- $\mathrm{HCl}, p \mathrm{H} 7.4$, including $0.9 \% \mathrm{NaCl})$. Dialyzed extracts derived from both normal and heterozygous subjects were diluted to similar protein concentrations (approximately $1.5 \mathrm{mg} / \mathrm{ml}$ ) and heated in a water bath at $46-48^{\circ} \mathrm{C}$. At time intervals an aliquot was removed and assayed for APRT activity. Activity remaining was expressed as a percentage of the activity in the unheated extract.

\section{RESULTS}

Blood from 18 subjects of the New Foundland family was obtained and erythrocyte APRT characterized. A pedigree of the family is illustrated in Fig. 1. These 18 subjects include a previously described homozygote for APRT deficiency, II-3 (Gault et al., 1981), and a homozygous deficient sibling, II-11, who is as yet asymptomatic.

\section{Erythrocyte Specific Activity and Immunoreactivity}

The specific activities of APRT in hemolysates from each of the 18 subjects are listed in Table I. Hemolysates from each of the two homozygotes have less than $1 \%$ of normal specific activity. Hemolysates from the 10 heterozygotes in this family exhibit a specific activity of APRT ranging from 20 to $39 \%$ of

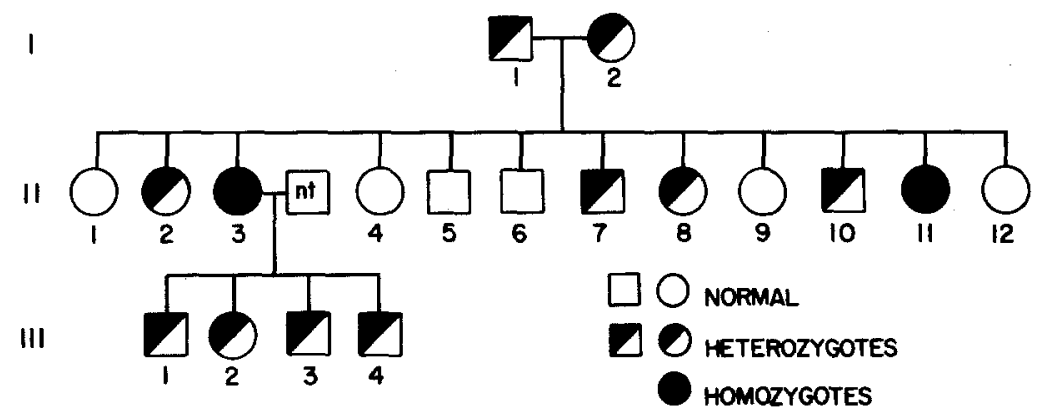

Fig. 1. Pedigree of the New Foundland family. nt, not tested. 


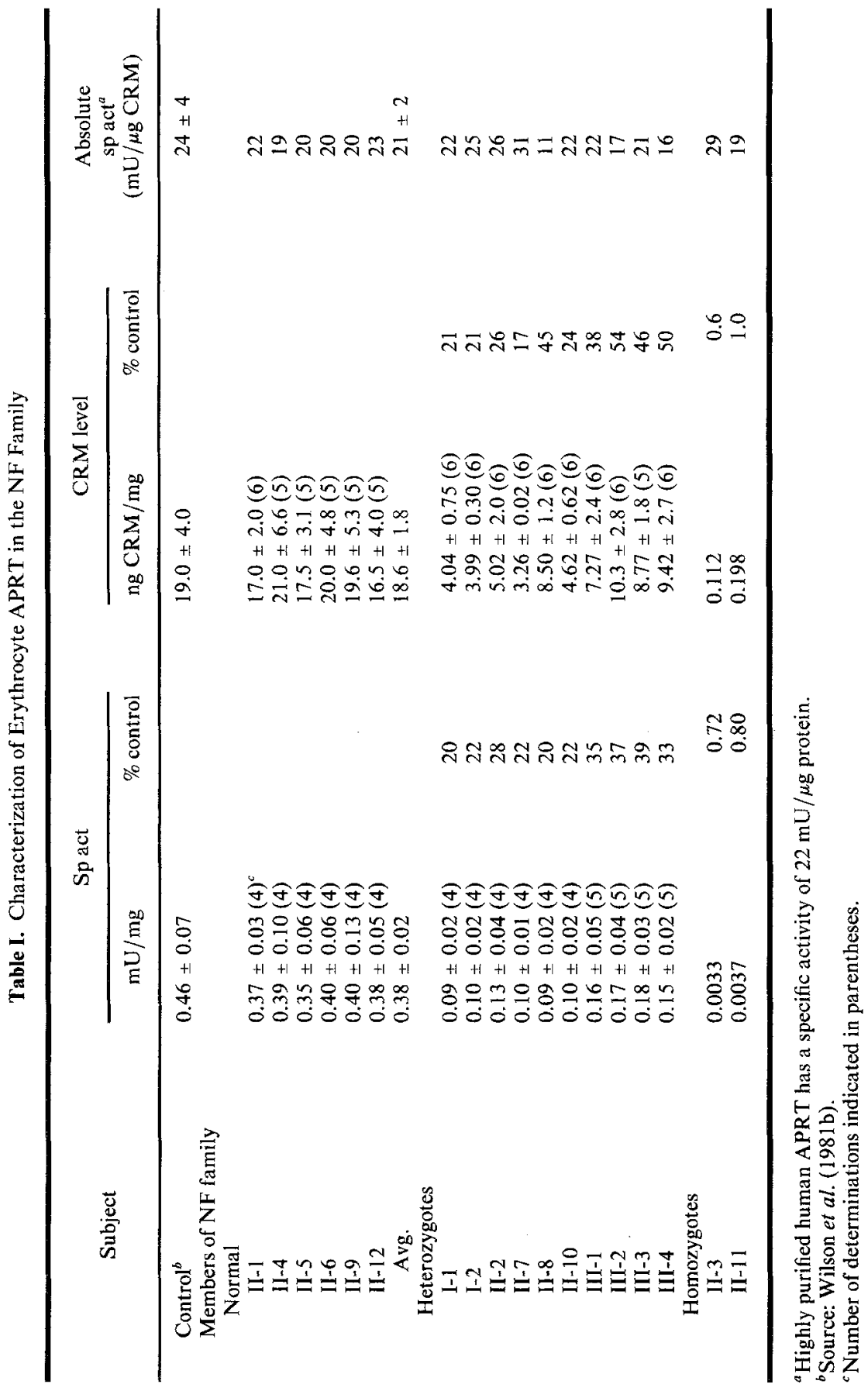


normal, with an average of $28 \%$. The six apparently normal subjects in the family have an average specific activity of $0.38 \mathrm{mU} / \mathrm{mg}$ in hemolysate, well within the published range (Wilson et al., 1981a).

Levels of immunoreactive APRT protein in hemolysate are also listed in Table I. Each homozygote had approximately 0.6 to $1 \%$ of the normal level. Heterozygotes had CRM levels ranging from 17 to $54 \%$ of normal, with an average of 34\%. The six normal patients had CRM levels in hemolysate well within the published range (Wilson et al., 1981a).

Within the heterozygotes there may be two separate ranges of activity and CRM. The parents and siblings of the two homozygotes have a specific activity ranging from 20 to $28 \%$ of normal, while four other heterozygotes, children of one homozygote, have an activity range from 35 to $39 \%$ of normal. In a similar fashion, the CRM level of heterozygous individuals in the first two generations ranges from 17 to $45 \%$ of normal, while CRM levels in the third generation of heterozygotes have a range of $38-54 \%$ of normal.

The absolute specific activity of APRT in hemolysate, the ratio of specific activity to CRM, is listed in Table 1 . In all cases including the two

Table II. Characterization of Erythrocyte HPRT in the NF Family

\begin{tabular}{cl}
\hline Subject & $\begin{array}{c}\text { Sp act } \\
(\mathrm{mU} / \mathrm{mg})\end{array}$ \\
\hline Control & $1.50 \pm 0.15^{a}$ \\
Members of NF family & \\
Normal & \\
II-1 & $1.23,1.65$ \\
II-4 & $1.68,1.73$ \\
II-5 & $1.75,1.69$ \\
II-6 & $1.18,1.61$ \\
II-9 & $1.35,1.61$ \\
II-12 & $1.49,1.52$ \\
Heterozygotes & \\
I-1 & $1.14,1.29$ \\
II-2 & $1.03,1.41$ \\
II-2 & $1.63,1.44$ \\
II-7 & $1.17,1.27$ \\
II-8 & $1.31,1.58$ \\
III-1 & $1.20,1.42$ \\
III-2 & $1.50,1.27$ \\
III-3 & $1.47,1.40$ \\
III-4 & $1.42,1.54$ \\
Homozygotes & $1.64,1.50$ \\
III-3 & $1.43,1.47$ \\
II-11 & $1.49,1.49$ \\
\hline
\end{tabular}

${ }^{a}$ Source: Wilson et al. (1981b). 


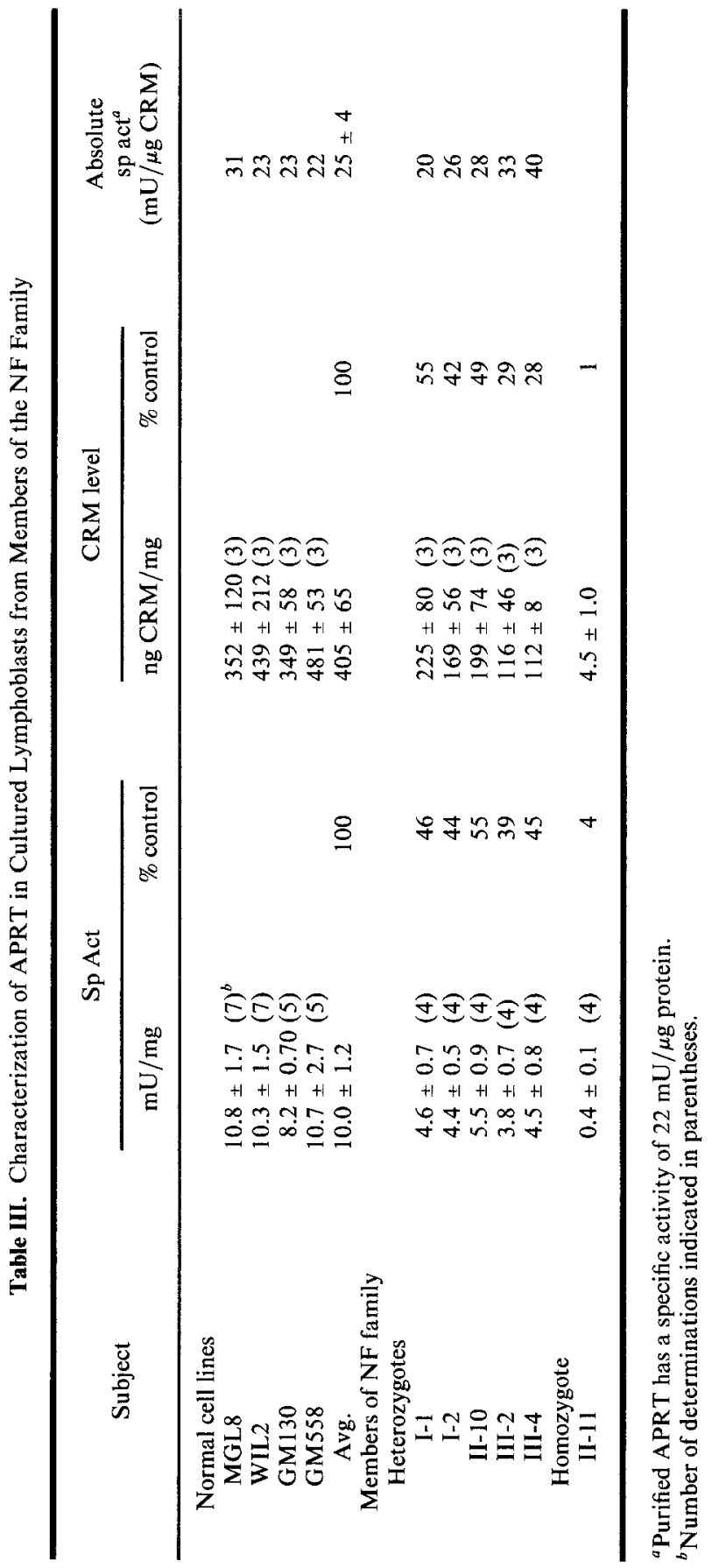


homozygotes studied, absolute specific activity was normal, except for subject II-8. In subject II-8 the absolute specific activity of APRT is about half of normal.

The specific activity of the purine salvage enzyme, HPRT, in hemolysate from each subject was indistinguishable from normal (Table II).

\section{Lymphoblast Specific Activity and Immunoreactivity}

The specific activities of APRT in extracts from the six cultured lymphoblast cell lines are listed in Table III. A normal range of lymphoblast APRT specific activity $(10.0 \pm 1.2 \mathrm{mU} / \mathrm{mg})$ was established in extracts from four cell lines,MGL8, WIL2, GM 130, and GM 558. The five heterozygotes studied had specific activities ranging from 39 to $55 \%$ of normal, with an average of $46 \%$, while the cell line derived from one homozygote had $4 \%$ of normal specific activity.

Levels of CRM in lymphoblasts extracts are also listed in Table III. Using the same four cell lines, a normal range was established ( $405 \pm 65 \mathrm{ng}$ $\mathrm{CRM} / \mathrm{mg}$ protein). The five heterozygotes tested had CRM levels ranging from 28 to $55 \%$ of normal, with an average of $41 \%$, while the homozygote had $1 \%$ of normal CRM.

The trend of separate ranges of activity and CRM between heterozygotes of the first two and the third generations, as observed in erythrocytes, is less apparent when the specific activity and CRM are determined from lymphoblast extracts.

The absolute specific activity of APRT in lymphoblasts is listed in Table III. Cells derived from each subject studied exhibited a normal absolute specific activity except for the cells from subject III-4, whose value may be slightly elevated. The absolute specific activity of APRT in both hemolysate and lymphoblast extracts is the same as that for the highly purified enzyme $(22 \mathrm{mU} / \mu \mathrm{g})$.

\section{Isoelectric Points}

Isoelectric focusing gels and protein blots were performed as described in Materials and Methods. An autoradiograph of an erythrocyte isoelectric focusing blot is shown in Fig. 2. Six heterozygotes (lanes A and B; F-I) showed identical migration with normal (lane $\mathrm{D}$ ). The two homozygotes (lanes $\mathrm{C}$ and E) do not have enough APRT CRM to be detected. A similar autoradiograph of an isoelectric focusing blot of APRT from cultured lymphoblasts is shown in Fig. 3. The five heterozygotes (lanes A, B, and E-G) have the same migration as normal (lane D) and only a single band is observed. The one homozygote studied (lane C) again had too little CRM to be detected. 


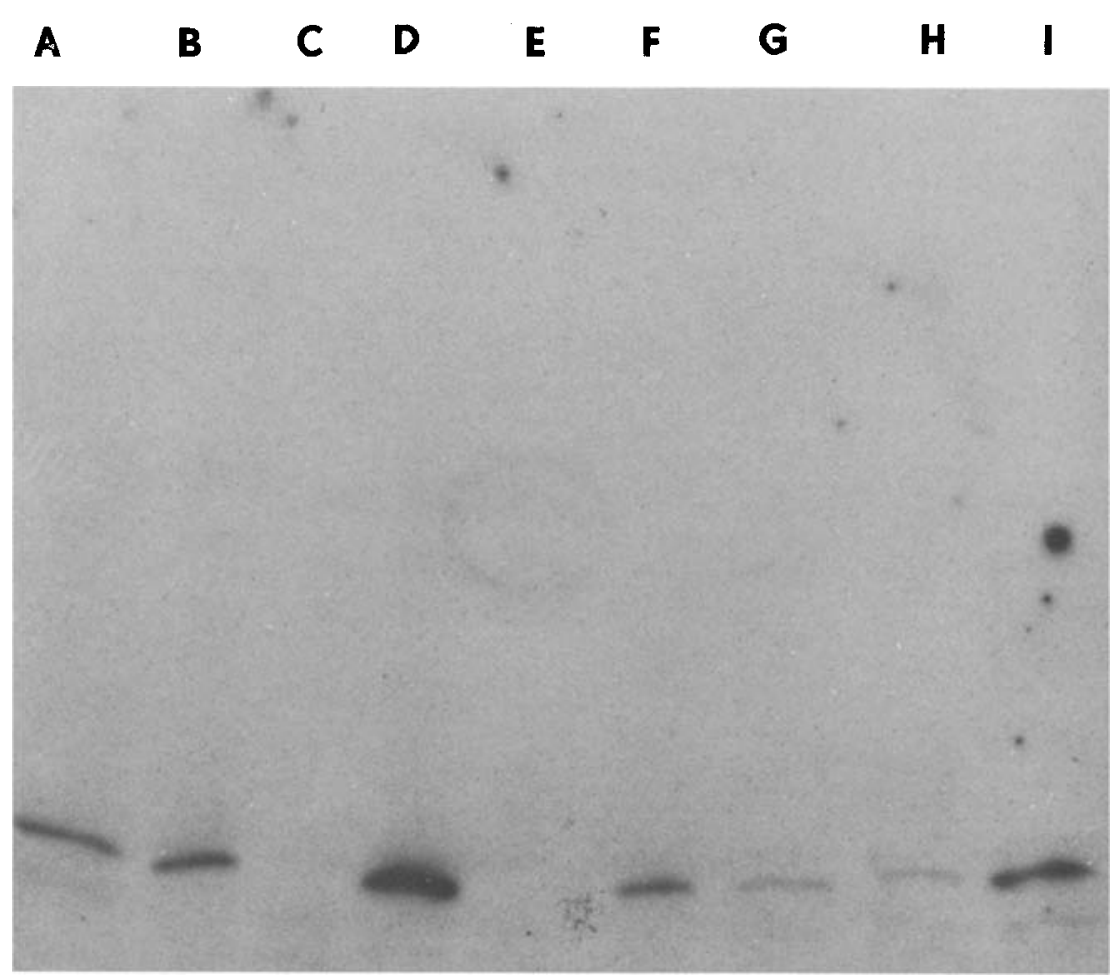

Fig. 2. Autoradiograph of erythrocyte isoelectric focusing blot of APRT. Isoelectric focusing protein transfer and immunochemical detection of APRT were done as described in Materials and Methods. Approximately equal amounts of protein were used in all lanes. Lane A, I-1; lane B, II-2; lane C, II-3; lane D, II-6; lane E, II-11; lane F, II-10; lane G, II-7; lane H, II-8; lane I, I-2. The isoelectric point of all enzymes is normal (lane D) and no reproducible second band is seen.

\section{Apparent Subunit Molecular Weight}

The electrophoretic migration of APRT under denaturing conditions was studied as described in Materials and Methods. An autoradiograph of a lymphoblast SDS PAGE blot is shown in Fig. 4. Four heterozygotes (lanes A-D) show identical migration to normal (lane F). The one homozygote (lane E) has too little CRM to be detected. A similar SDS PAGE blot of APRT partially purified from hemolysate of heterozygous and normal subjects has exhibited no abnormal migration (data not shown).

\section{Heat Stability}

The five heterozygous and one normal (WIL2) lymphoblast cell line were studied with regards to heat stability as described in Materials and Methods. 


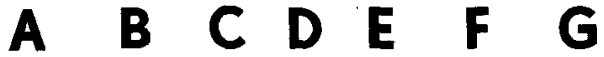

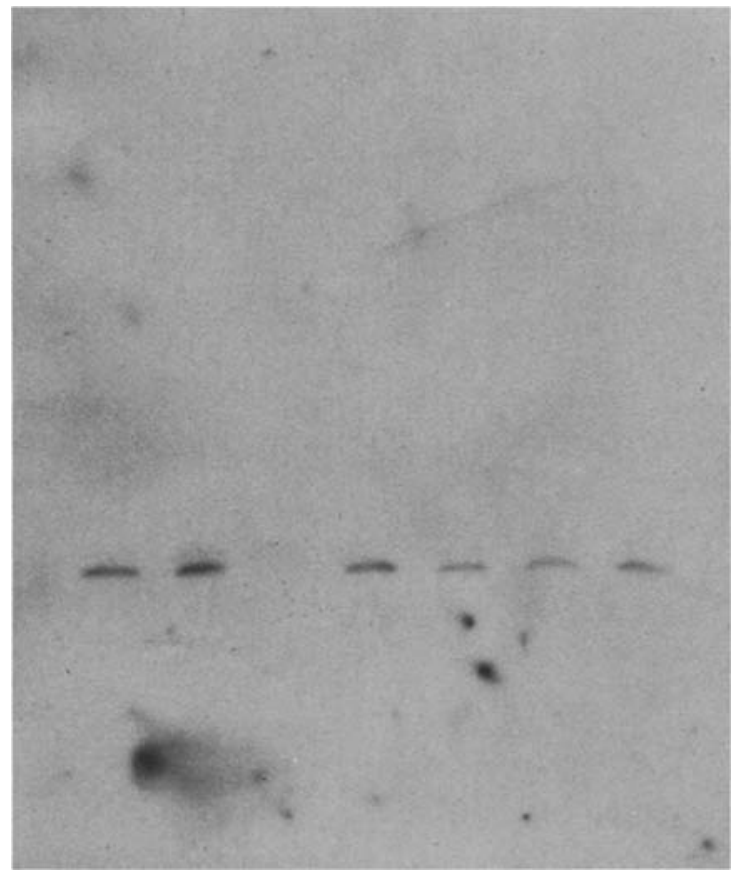

Fig. 3. Autoradiograph of lymphoblast isoelectric focusing blot of APRT. Isoelectric focusing protein transfer and immunochemical detection of APRT were done as described in Materials and Methods. Approximately equal amounts of protein were used in all lanes. Lane A, II-10; lane B, III-4; lane C, II-11; lane D, MGL8; lane E, I-2; lane F, III-2; lane G, I-1. The isoelectric point of all enzymes is normal (lane $\mathrm{D}$ ) and no second band is seen.

The rate of loss of APRT activity appears identical in lymphoblast extracts from both normal and heterozygous individuals (Fig. 5).

\section{DISCUSSION}

Previous studies of APRT deficiency using erythrocytes from affected individuals revealed the unique occurrence of unusually low levels of APRT in heterozygotes (Kelley et al., 1968; Wilson et al., 1981a). Because erythrocytes are enucleated and do not have the genetic machinery of a dividing cell, however, this cell type was not the most suitable for studying the properties of APRT gene expression. For this reason we have chosen to study the properties of APRT in cultured lymphoblasts derived from enzyme deficient subjects in 


\section{A B C D E F}

Fig. 4. Autoradiograph of SDS PAGE blot of APRT. SDS-polyacrylamide gel electrophoresis, protein transfer, and immunochemical detection of APRT were done as described in Materials and Methods. Approximately equal amounts of protein were used in all lanes. Lane A, I-1; lane B, III-2; lane C, II-10; lane D, III-4; lane E, II-11; lane F, WIL2. The migration of all enzymes is identical to normal (lane F) and no second band is seen.

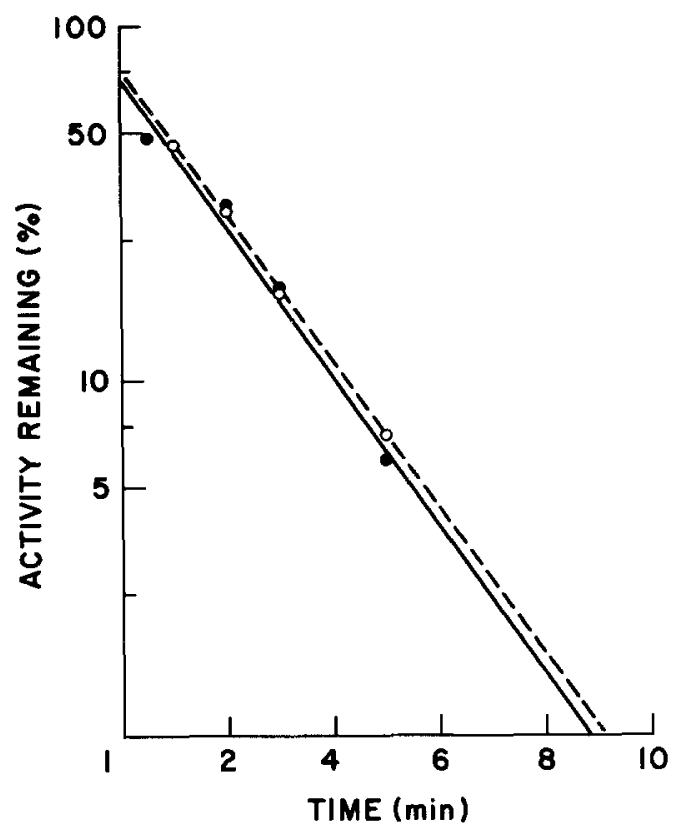

Fig. 5. Representative semilog plot of the heat stability of lymphoblast APRT. Heat stability experiments were conducted as described in Materials and Methods and the rate of loss of APRT activity was determined via linear regression analysis. Filled circles and solid line, WIL2. Open circles and dashed line, II-10.The rate of activity loss in the four other heterozygotes studied is indistinguishable. 
one family and to compare the findings with results obtained in hemolysate from the same individuals. We have, therefore, examined APRT in erythrocytes from 18 subjects spanning three generations in a single kindred and in cultured lymphoblasts from 6 of these 18 subjects.

In the present study, the specific activity of APRT in erythrocytes from heterozygotes averaged $28 \%$ of normal, while CRM levels were $34 \%$ of normal. The levels of activity and CRM in homozygotes were less than $1 \%$ of normal. These findings confirm our earlier study of other families (Wilson et al., 1981a), again noting that heterozygotes have levels of enzyme activity substantially lower than the expected $50 \%$ of normal. Using cultured lymphoblasts, however, levels of APRT specific activity and CRM are close to the expected $50 \%$ level.

The higher levels of APRT activity found in cultured lymphoblasts derived from heterozygotes is consistent with the model proposed earlier to account for the low level of erythrocyte APRT activity in heterozygotes. Because lymphoblasts are actively synthesizing new protein, "hybrid" dimers, composed of one normal and one mutant subunit, may exist even though they are abnormally labile. Thus, in cultured lymphoblasts derived from heterozygotes, the activity and CRM levels represent a combination of that contributed by normal:normal dimers and that contributed by normal:mutant dimers which have yet to lose activity. According to this hypothesis, such mutant gere expression and the existence of a putative "hybrid" dimer are not seen in erythrocytes because this labile protein species is degraded too rapidly. Molecular variants of peptidase A (Sinka et al., 1970; Lewis, 1973), isocitrate dehydrogenase (Turner et al., 1973), and peptidase C (Povey et al., 1972) are other examples where mutant gene expression is observed in other tissues but not in erythrocytes, presumably for the reason noted above. Alternately, the higher levels of activity and CRM found in cultured lymphoblasts may be due to a compensatory mechanism in the cell which increases the expression of the normal allele, while either the mutant allele is not expressed or its product is labile and undetectable by these assays. In this case, presumably, such metabolic regulation or compensation of APRT levels is not possible with erythrocytes, and consequently only levels of about $25 \%$ of normal are observed.

In our efforts to distinguish between these possibilities, we have attempted to find evidence for the existence of a mutant gene product by examining the isoelectric point, electrophoretic migration under denaturing conditions, and heat stability of APRT in erythrocytes and cultured lymphoblasts from subjects heterozygous for APRT deficiency in a single family. In our previous study (Wilson et al., 1981a), an apparent mutant APRT subunit which had a more acidic isoelectric point was detected in hemolysate from one subject. In this study, however, the isoelectric point and electrophoretic 
migration of erythrocyte APRT from all heterozygotes were indistinguishable from normal. While expression of the mutant allele should have been more readily detectable in cultured lymphoblasts, the isoelectric point, electrophoretic migration, and heat stability of lymphoblast APRT were identical to normal in the five heterozygotes studied, with no evidence of an altered gene product as we also observed in hemolysate from these subjects. Resolution of this question will probably require an analysis of the levels of APRT mRNA in appropriate tissue from subjects who are heterozygous for APRT deficiency.

In this study we have demonstrated a difference in APRT activity and CRM levels between erythrocytes and lymphoblasts derived from subjects heterozygous for APRT deficiency in one large family. Although we have suggested mechanisms to account for this difference, we were not able to distinguish between them at this time. Such a difference, however, leads us to suggest the desirability of lymphoblasts as the tissue of choice for further studies of the molecular mechanisms involved in APRT deficiency. Not only are lymphoblasts actively synthesizing new protein for studying the molecular and physical properties of APRT, but also they may serve as a source of DNA and RNA for studying the dynamic processes of normal and abnormal gene expression. In a similar fashion, lymphoblasts have been suggested as the tissue of choice in studying the mechanisms of other inborn errors of metabolism such as HPRT deficiency (Wilson et al., 1982).

\section{REFERENCES}

Barratt, T. M., Simmonds, H. A., Cameron, J. S., Potter, C. F., Rose, G. A., Arkell, D. G., and Williams, D. I. (1979). Complete deficiency of adenine phosphoribosyltransferase. A third case presenting as renal stones in a young child. Arch. Dis. Child 54: 25.

Debray, H., Carter, P., Temstet, A., and Cendron, J. (1976). Child's urinary lithiasis revealing a complete deficit in adenine phosphoribosyltransferase. Pediat. Res. 10: 762.

Fox, I. H., Meade, J. C., and Kelley, W. N. (1973). Adenine phosphoribosyltransferase deficiency in man. Report of a second family. Am. J. Med. 55:614.

Gault, H. M., Simmonds, H. A., Snedden, W., Dow, D., Churchill, D. N., and Penney, H. (1981). Urolithiasis due to 2, 8-dihydroxyadenine in an adult. N. Engl. J. Med. 305:1570.

Holden, J. A., and Kelley, W. N. (1978). Human hypoxanthine-guanine phosphoribosyltransferase: Evidence for a tetrameric structure. J. Biol. Chem. 253:4459.

Holden, J. A., Meredith, G. S., and Kelley, W. N. (1979). Human adenine phosphoribosyltransferase: Affinity purification, subunit structure, amino acid composition, and peptide mapping. J. Biol. Chem. 254:6951.

Kelley, W. N., Levy, R. I., Rosenbloom, F. M., Henderson, J. F., and Seegmiller, J. E. (1968). Adenine phosphoribosyltransferase deficiency: A previously undescribed genetic defect in man. J. Clin. Invest. 47:2281.

Lewis, W. H. P. (1973). Common polymorphism of peptidase A. Electrophoretic variants associated with quantitative variation of red cell levels. Ann. Hum. Genet. Lond. 36:267.

Lowry, O. H., Rosebrough, N. V., Farr, A. L., and Randall, R. J. (1951). Protein measurement with the Folin phenol reagent. J. Biol. Chem. 193:265.

Povey, S., Corney, G., Lewis, W. H. P., Robson, E. B., Parrington, J. M., and Harris, H. (1972). The genetics of peptidase $\mathrm{C}$ in man. Ann. Hum. Gen. Lond. 35:455. 
Sinka, K. P., Lewis, W. H. P., Corney, G., and Harris, H. (1970). Studies on the quantitative variation of human red cell peptidase A activity. Ann. Hum. Gen. Lond. 34:153.

Turner, B. M., Fisher, R. A., Garthwaite, E., Whale, R. J., and Harris, H. (1973). An account of two new ICD-S variants not detectable in red blood cells. Ann. Hum. Gen. Lond. 37:469.

VanAcker, K. J., Simmonds, H. A., Potter, C. F., and Cameron, J. S. (1977). Complete deficiency of adenine phosphoribosyltransferase: Report of a family. N. Engl. J. Med 297:127.

Wilson, J. M., Daddona, P. E., Simmonds, H. A., VanAcker, K. J., and Kelley, W. N. (1981a). Human adenine phosphoribosyltransferase: Immunochemical quantitation and protein blot analysis of mutant forms of the enzyme. J. Biol. Chem. 257:1508.

Wilson, J. M., Baugher, B. W., Landa, L., and Kelley, W. N. (1981b). Human hypoxanthineguanine phosphoribosyltransferase: Purification and characterization of mutant forms of the enzyme. J. Biol. Chem. 256:10306.

Wilson, J. M., Baugher, B. W., Mattes, P. M., Daddona, P. E., and Kelley, W. N. (1982). Human hypoxanthine-guanine phosphoribosyltransferase: Demonstration of structural variants in lymphoblastoid cells derived from patients with a deficiency of the enzyme. J. Clin. Invest. 69:706. 